\title{
Selected properties of laser cladding coatings shaped using Flow drill technology
}

\author{
Dariusz Bartkowski ${ }^{1}{ }^{*}$, Waldemar Matysiak ${ }^{1}$, and Aneta Bartkowska ${ }^{2}$ \\ ${ }^{1}$ Poznan University of Technology, Faculty of Mechanical Engineering and Management, Institute of \\ Materials Technology, Poznan, Poland \\ ${ }^{2}$ Poznan University of Technology, Faculty of Mechanical Engineering and Management, Institute of \\ Materials Science and Engineering, Poznan, Poland
}

\begin{abstract}
The paper presents the investigations of selected chemical and mechanical properties as well as macro- and microstructure of materials formed using thermal drilling process (Flow drill). The aim of this study was to determine the microstructure of the coatings produced using laser cladding with powder technology. The coatings were produced on the lowcarbon steel using $1 \mathrm{~kW}$ disc laser. After modification of surface, the thermal drilling process was applied. To produce all coatings, the pure copper powder was used. In this study the laser power equal of 500, 700 and $900 \mathrm{~W}$ were used. The microstructure, chemical composition (EDS) and microhardness were investigation. It was found that the surface modification of low carbon steel and next conducted thermal drilling process caused change the surface properties on the hole flange. It was found that surface modification of steel using laser cladding with cooper powder and next Flow drill process contributes to the change in microhardness and chemical composition on hole flange.
\end{abstract}

\section{Introduction}

Surface engineering technologies have influenced on the development of other production technologies and materials processing such as surface modification [1 - 13] as well as metal forming processing [14-22]. One of the metal forming processes is the hole flanging which is intended to increase the diameter of the previously cut hole and to form around it the conical or cylindrical flange. The traditional method is commonly known and consists of flanging through the cylindrical punch with a tapered end which is intended to pierce through the material pointwise and then to form a corresponding hole shape and a flange around it. Technological advances have strongly influenced the conventional edge drilling technology by Flow drill technology. Many characteristics of this process have benefited from it compared to the older known processing methods. There are several important advantages of this process $[14,15]$. Firstly, in the thermal drilling process there is no material loss. Material is plasticized and then formed. Thanks to this, material is fully utilized to fabricate the collar and forming the sleeve. Additionally the Flowdrill technology allows the produces sleeve up to three times the height of the output material. Material

\footnotetext{
* Corresponding author: dariusz.bartkowski@put.poznan.pl
} 
thickness may range from 0.5 to $10 \mathrm{~mm}$. A slight increase in the recommended values of the machining parameters allows the edge thickness to increase by several percent. The thermal drilling is a one-step process, it does not require any change of tools or additional treatment before and after the process, and the time needed to produce the hole flange is small, just a few seconds. In addition, this process is very fast and easy to automate, making it suitable for serial or mass production.

This work is focused on the issue of the hole flanging using the thermal drilling technology (Flow drill). The process was used on materials with coating produced by the laser cladding process which is commonly used $[1-4,11]$. Selected properties such as macro- and microstructure, coating thickness, microhardness, and chemical composition were investigated. The results were analysed and they are very promising.

\section{Research Methodology}

\subsection{Materials and technology}

The output material used for the laser cladding and thermal drilling processes was the general purpose structural S235JRH steel. It chemical composition of this material was shown in Table 1.

Table 1. Chemical composition of S235JRH steel used for testing.

\begin{tabular}{|c|c|c|c|c|c|}
\hline \multirow{2}{*}{ Steel grade } & \multicolumn{5}{|c|}{ Maximum weight share [\%] } \\
\cline { 2 - 6 } & $\mathrm{C}$ & $\mathrm{Mn}$ & $\mathrm{P}$ & $\mathrm{S}$ & $\mathrm{N}$ \\
\hline $\mathrm{S} 235$ & 0.7 & 1.40 & 0.045 & 0.045 & 0.009 \\
\hline
\end{tabular}

Specimens of $30 \times 24 \times 20 \mathrm{~mm}$ with a wall thickness of $2 \mathrm{~mm}$ were cut from the profile. On the specimens were produced cooper coatings using laser cladding technology. On the series of specimens of S235JRH steel the copper coatings using laser beam have been made. The manufacturing process was carried out at the Industrial Institute of Agricultural Machines in Poznan. The TRUMPF laser model TruLaser Cell 3008 was used for produced specimens for research. The working area of this device includes the axes: $\mathrm{X}-800 \mathrm{~mm}, \mathrm{Y}$ $500 \mathrm{~mm}$ and $\mathrm{Z}-400 \mathrm{~mm}$. The laser device includes components such as a working chamber, TruDisk $1000 \mathrm{~W}$ disk laser equipped with a three-stream powder feeding system as well as cooling and filtering circuits. Prior to making the coatings, the specimens must be properly prepared: the surface of each was polished and cleaned. The laser cladding process was carried out in a closed chamber where powdered material was supplied coaxial to the laser beam by carrier gas as shown in Figure 1 .

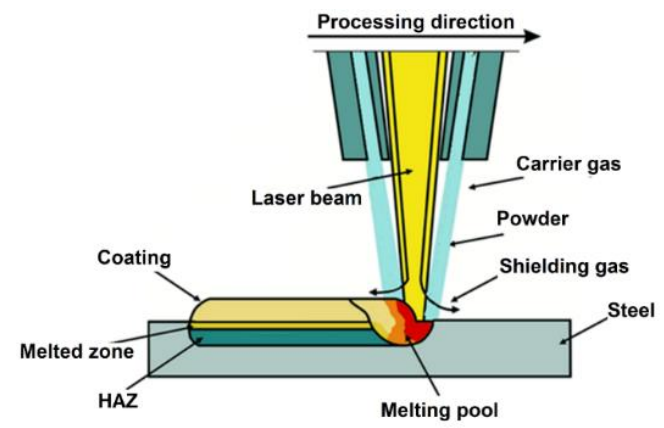

Fig. 1. Scheme of a laser cladding process with additive material in the form of powder. 
The laser head contains three powder delivery nozzles and a central channel through which the shield gas and the laser beam are supplied. The coatings were prepared for each specimens using varying laser power parameter $(700,800$ and $900 \mathrm{~W})$. The process was carried out with constant parameters: feedrate $600 \mathrm{~mm} / \mathrm{min}$; laser beam diameter $2 \mathrm{~mm}$; flow rate of gas supplying the powder (helium) $81 / \mathrm{min}$; shield gas flow rateo (argon) 8 $1 / \mathrm{min}$; powder feeder rate $0.8 \mathrm{obr} / \mathrm{min}$.

Specimens with laser cladded coating were subjected to a flow drill process. Holes and flanging for each specimens were made on a JET JMD-18VS drilling machine. The machine was equipped with a handle with cooling ring in which a drill bit of $7.3 \mathrm{~mm}$ was mounted. The tool was secured with a Flowdrill FDKS paste that was applied each time before the hole was made to protect the tool from high temperatures. Tools turnover amounted to $3000 \mathrm{rev} / \mathrm{min}$, and feed rate was performed manually. Figure 2 shows a scheme of the hole flanging process in materials with coating produced using laser cladding with powder technology.

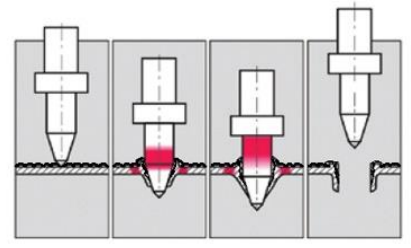

Fig. 2. Scheme of flanging using Flowdrill technology in materials with laser cladded coating.

\subsection{Microstructure and microhardness study}

Macroscopic observation of all specimens was performed using the magnifying glass. Color as well as presence or absence of cracks and porosity were determined. Photos were taken using the Nikon D5000. Microstructural observations were made using Huvitz HRM-300 optical microscope with digital image recording. For the tests, metallographic cross section were made. The specimens were cutting and next placing in conductive thermoset resin. To reveal the microstructure of specimens substrate and its surface, the mixture of nitric acid and ethanol was used. Microhardness tests were performed using the Vickers method on the Buehler microhardness tester.

\subsection{Chemical composition study}

The chemical composition of specimens was examined using the scanning electron microscope (SEM) Vega Tescan equipped with PGS's Prism 2000 EDS (Energy Dispersive Spectroscopy) system. EDS analyzers allow both surface and volumetric identification of the chemical elements contained in the test material. A linear analysis of the chemical composition was carried out for each specimen.

\section{Results of study}

\subsection{Microstructure and microhardness results}

In Figure 3 were shown a macroscopic images of three samples with coatings produced using different laser beam powers. For the first specimen $(700 \mathrm{~W})$, it can be seen that the resulting coating has a copper color without discoloration and other changes. Width of tracks are the same. No deformation and no cracks were observed. For the specimen 
produced using laser beam power equal $800 \mathrm{~W}$, the part of surface have color of copper, but slightly darker than on first specimen. It was also found the dark area that results from excessive heating of the workpiece during the laser cladding process. In addition, no cracks, porosities or other surface damage were noted. In the case of specimen produced using laser beam power equal $900 \mathrm{~W}$, the surface is mostly gray with one track of copper-colored track. Deformation of track was much greater than that preevious specimens. Based on macroscopic examination of three series kind of specimens produced using different laser beam power, it was found that the hole flanging process was successful and the form of holes and flange of all specimens were very similar. No geometric defects were observed in the form of cracks or other discontinuities of the material.

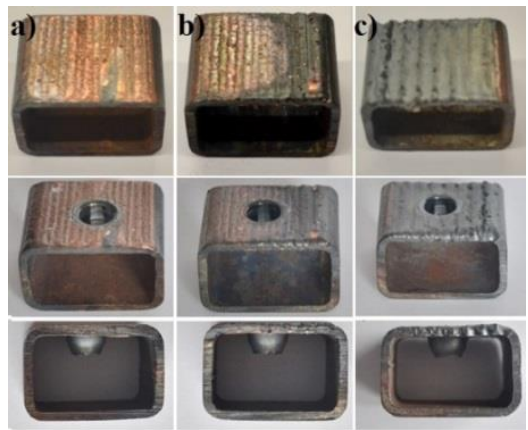

Fig. 3. Specimens with coating produced using laser cladding at laser beam power and after Flowdrill a) $700 \mathrm{~W}$ b) $800 \mathrm{~W}$ and c) $900 \mathrm{~W}$.

On the basis of the conducted examinations of metallographic cross section of specimens the microstructure was determined. The results of microstructure were shown in Figure 4. In the case of specimens produced using laser beam power of $700 \mathrm{~W}$, there are three distinct zones in the material: a distinctly uneven copper layer, a transition layer, and the substrate.

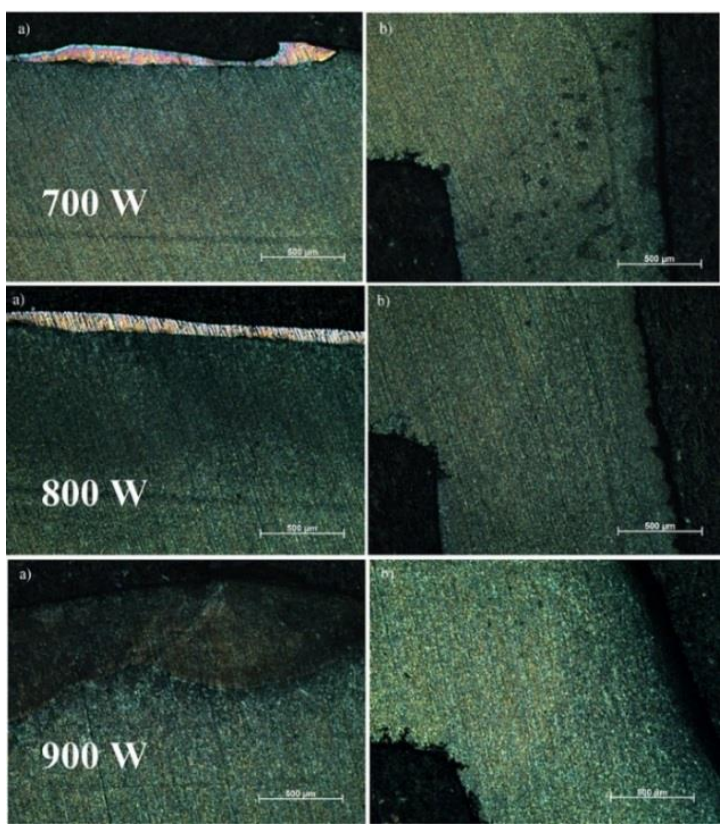

Fig. 4. Microstructure of a specimen with a laser cladded coating of cooper : a) coating, b) hole flange. 
On the hole flange edge, it was found that the distinctive copper coating disappears, leaving only the transition zone. In the case of specimens produced using laser beam power of $800 \mathrm{~W}$, there also three separate zones. This time the copper coating is spread evenly over the whole length, and it disappears on the edge of hole flange. The microstructure of specimen produced using laser beam power of $900 \mathrm{~W}$, clearly differs from the previous. Higher temperature of laser claddind process caused the copper powder was mixed with the substrate material to a much greater extent than in the case of two previous kind of specimens. This results in a thicker outer coating without copper-colored and a difficult-tofind border of the transition zone. It is also possible to observe the absence of pores within the rim of the rolled edge. Microstructural studies additionally included a microhardness test of hole flange. For each specimens, five measurements were made in the cross section of the flange from the inner wall to the inside of the material. The results microhardness measurments for all specimens are present in table 2 .

Table 2. Microhardness of specimens.

\begin{tabular}{|c|c|c|c|}
\hline \multirow{2}{*}{$\begin{array}{c}\text { Measurement } \\
\text { number }\end{array}$} & $\mathbf{3}$ & Microhardness [HV] \\
\cline { 2 - 4 } & $\mathbf{7 0 0 W}$ & $\mathbf{8 0 0 W}$ & $\mathbf{9 0 0 W}$ \\
\hline 1 & 255 & 236 & 221 \\
\hline 2 & 220 & 199 & 176 \\
\hline 3 & 196 & 161 & 213 \\
\hline 4 & 274 & 213 & 171 \\
\hline 5 & 220 & 193 & 171 \\
\hline Average: & 233 & 200.4 & 190.4 \\
\hline
\end{tabular}

The highest micro hardness value was achieved with the specimen produced using laser beam power equal to $700 \mathrm{~W}$. This hardness was about $22 \%$ larger than the specimen produced at $900 \mathrm{~W}$ and about $16 \%$ larger than the specimens produced using $800 \mathrm{~W}$. With the increase in laser beam power, the substrate was melted and mixed with the coating material, which is harder than substrate. Hence, at the smallest power of the laser beam, the surface of the flange is characterized by the highest microhardness. Increasing the power of the laser beam causes mixing the coating material with the soft substrate.

\subsection{Chemical composition study}

A linear analysis of the chemical composition of the specimens was made. Content of copper and iron was determined (Fig. 5). From the diagram (700 W), it can be determined that the produced coating have about $100 \mu \mathrm{m}$ thickness in the material. The copper content on the surface varies considerably from about $75 \%$ to $40 \%$, and beyond this $100 \mu \mathrm{m}$, a sharp decrease in the percentage of copper and a stabilization of about $5 \%$ was observed. In contrast to copper, the concentration of iron was change. For specimen produced using 800 $\mathrm{W}$, the situation is similar to that of the specimen produced using $700 \mathrm{~W}$. The coating containing copper concentration of about $50 \%$ reached $70 \mu \mathrm{m}$ deep into the test material. The initial high content of $80 \%$ quickly declined, stabilizing between $45 \%$ and $65 \%$. This time the iron content was interwoven with the copper in the top layer, where the rise and fall were recorded, but the value itself did not exceed 55\%. As the graph shows, after a distance of $70 \mu \mathrm{m}$, the content of the elements has been stabilized after a visible drop of copper concentration to about $5 \%$ and a sharp increase in iron concentration to about $95 \%$. In the case of specimen produced using $900 \mathrm{~W}$, a large difference in the course of the concentration change can be observed compared to the other two kind of specimens. The copper content in the top of coating did not exceed $60 \%$ and to about $120 \mu \mathrm{m}$ did not decrease below 50\%. Iron content in the top of coating was the highest of all three 
specimens, its concentration ranged between 40 and $50 \%$. Closer to the steel substrate there is a gradual decrease in copper content and an increase in iron content which, as in previous cases, has stabilized, reaching values of about $5 \%$ for copper and about $95 \%$ for iron approximately $260 \mu \mathrm{m}$ from surface.

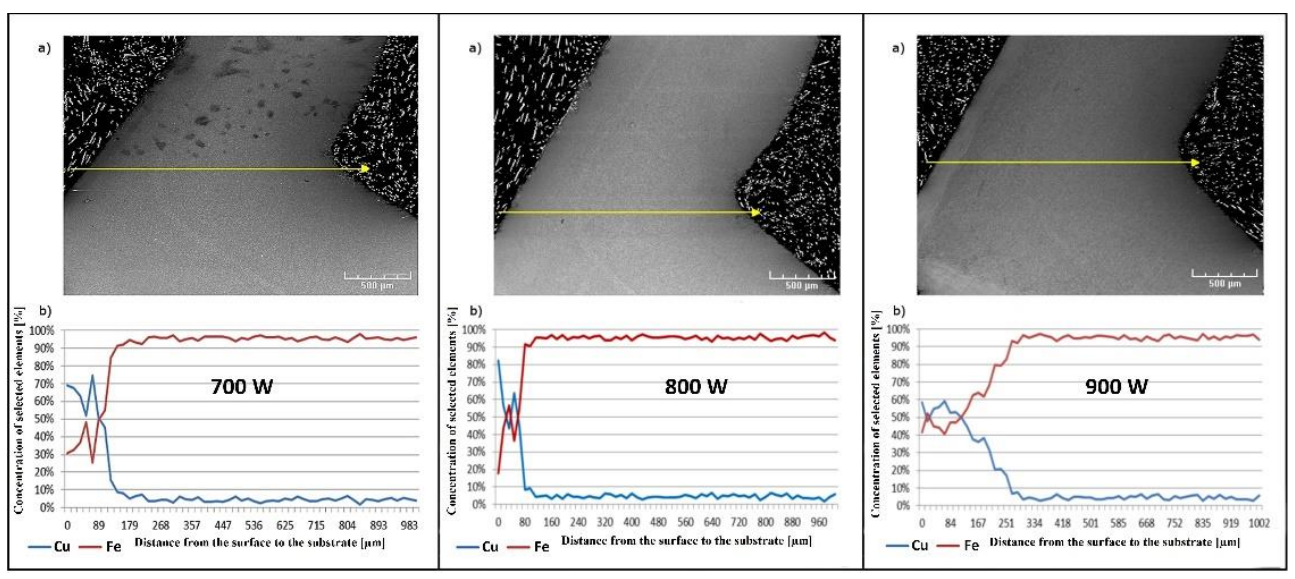

Fig. 5. Chemical composition of specimen with cooper coating produced using laser cladding: a) direction of linear composition analysis $\mathrm{b}$ ) concentration of $\mathrm{Fe}$ and $\mathrm{Cu}$.

\section{Conclusions}

Both technology presented in this work, laser cladding as well as Flowdrill are innovative technologies. Combining these two processes allows get high-quality connections in a very short time. Additionaly both of these methods are very quick and easy to automate. Laser cladding and Flowdrill processes are characterized by the fact that they are based on the treatment of elements with very high temperatures.

Based on this studies can be drawn the following conclusions. From the macrostructure study, it appears that the copper layer made with laser technology did not negatively affect the quality of the hole flange. For all three kind of specimens no discoloration, cracks or porosities were observed and the inner surface of the flange was good quality. Analysis of the chemical composition showed an increased copper concentration at the inner wall of flange. The process of thermal drilling caused the diffusion of coating material to the steel substrate. The method described may be used in the case of joining materials which have previously been subjected to surface treatment.

\section{References}

1. M. W. Steen, J. Mazumder, Laser Material Processing. Springer (2010)

2. D. Bartkowski, A. Bartkowska, IJRMHM 64 20-26 (2017)

3. D. Bartkowski, G. Kinal, Int J Refract Met H 58, 157-164 (2015)

4. D. Bartkowski, A. Młynarczak, A. Piasecki, B. Dudziak, M. Gościański, A. Bartkowska, Opt Laser Technol 68 191-201 (2015)

5. A. Bartkowska, A. Pertek, M. Jankowiak, K. Jóźwiak, Archiv Metall Mater 57, 211 214 (2012)

6. A. Bartkowska, A. Pertek, Surf Coat Tech 248, 23-29 (2014)

7. W. Li, K. Yang, D. Zhang, X. Zhou, J Therm Spray Techn 25, 1-2 (2016)

8. S-J. Dong, B. Song, G-S. Zhou, J Therm Spray Techn 22, 7 (2013) 
9. R. Gr. Maev, V. Leshchynsky, E. Strumban, J Therm Spray Techn 25, 1-2 (2016)

10. M. Reza Bateni, P. Wei, O. Kesler, A. Petric, Mater Manuf Process 28 (2013)

11. A. R. Yan, Y-J. Li, Z-Y. Wang, Lasers in Eng 29, 365-377 (2014)

12. V. Torabinejad, A. Sabour Rouhaghdam, M. Aliofkhazraei, Bulletin of Materials Science 39, 3 (2016)

13. E. Abakay, S. Sen, U. Sen, Acta Physica Polonica 129 (2016)

14. W. Matysiak, L. Bernat, Metalurgija 54, 235-238 (2015)

15. A.H. Streppel, H.J.J. Kals, CIRP Annals 32, 167-171 (1983)

16. C. Bates, American Machinist 152, $56-58$ (2008)

17. S. F. Miller, J. Tao, A. J. Shih, Int J Mach Tool Manu 46, 1526-1535 (2006)

18. L. Sobotová, J. Kmec, L. Bičejová, IJE, IX 1584-2673 (2011)

19. H.-M. Chow, S.-M. Lee, L.-D. Yang, J Mater Process Tech 207, 180-186 (2008)

20. W. Matysiak, B. Barišić, I. Mamuzić, Metabk 49, 13-17 (2010)

21. W. Matysiak, Metal forming 4, 49-57 (2005)

22. S. Dobatkin, J. Zrnik, I. Mamuzic, Metalurgija 48, 157-160 (2009) 
